\title{
Barriers and challenges to smart buildings' concepts and technologies in Brazilian social housing projects
}

\author{
José Alcides Gobbo Junior* and \\ Maria Goretti Zago Nunes de Souza
}

Department of Production Engineering, UNESP - Universidade Estadual Paulista,

Av. Eng. Luiz Edmundo Carrijo Coube, 14-01, 17033-360 Bauru-SP, Brazil

Email: gobbo@feb.unesp.br

Email:mgzago@uol.com.br

*Corresponding author

\section{Simone Cristina de Oliveira Gobbo}

EESC - School of Engineering of São Carlos,

USP - University of São Paulo,

Avenida Trabalhador São Carlense, 400, 13566-590 São Carlos-SP, Brazil

Email: sigobbo@sc.usp.br

\begin{abstract}
Smart building research is commonly explored in commercial buildings and less studied in the context of social housing. In this context, this article aims to diagnose the main barriers to the adoption of smart buildings' concepts and technologies in social housing projects in Brazil. The 'Expert Interviews' method was used with seven Brazilian experts in the fields of smart buildings and social housing, based on the assumption that experts have special knowledge, which are related to a special field. The main barriers categories identified in this study can be summarised in: 1) economic; 2) policy; 3) social; 4) technical. Based on these results, the study aims to contribute with possible solutions and guidelines to overcome such barriers, and discusses propositions that can be improved into hypothesis for later empirical testing.
\end{abstract}

Keywords: smart building; smart home; barrier; social housing; expert interview; smart homes; building technologies; smart grid; smart meters; sustainable buildings.

Reference to this paper should be made as follows: Gobbo Jr., J.A., de Souza, M.G.Z.N. and Gobbo, S.C.O. (2017) 'Barriers and challenges to smart buildings' concepts and technologies in Brazilian social housing projects', Int. J. Sustainable Real Estate and Construction Economics, Vol. 1, No. 1 , pp.31-50.

Biographical notes: Jose Alcides Gobbo Junior received his $\mathrm{PhD}$ in Business Administration from Fundação Getulio Vargas - FGV-SP in 2004. He is an Associate Professor at Engineering Faculty of UNESP, Sao Paulo State University, where he coordinated the post-graduate program in production engineering and act as a referee in a number of journals. He has experience in production engineering focusing on the following subjects: innovation, networks and packaging logistics. 
Maria Goretti Zago Nunes de Souza received her degree in Electrical Engineering from the University of São Paulo in 1985. She received her Master's degree in Electrical Engineering from the State University of Campinas in 1992 and Doctorate from the Polytechnic School of the University of São Paulo in 2012. She acted in an industry of the electricity sector for a period of 18 years in the areas of design, production management and quality. She is currently a Professor at the Bauru School of Technology - FATEC Bauru - in technology courses in biomedical systems technology database technology in computer networks. Her areas of interest are energy efficiency, energy management and environmental management, electrical transformers, automation and mechatronics, intelligent systems, quality systems, production management and business administration.

Simone Cristina de Oliveira Gobbo is a PhD student in Production Engineering at University of São Paulo (USP), Brazil. She received her Master's degree in Production Engineering (2010) from São Paulo State University (UNESP), Bachelor's degree in Economics (2002), and MBA (2007) from Methodist University of Piracicaba (UNIMEP). Her main research subject is social network analysis in manufacturing and healthcare.

\section{Introduction}

Many buildings are equipped with systems to collect a large number of data during operation, energy consumption and activities through systems such as the building management system (BMS), sensors and meters (Lee et al., 2013). They are called smart building because they provide dynamic, real-time control over an increasing variety of building activities in response to a range of internal and external data streams (Smart Cities Council, 2015). According to Zainordin et al. (2012), the smart building concept is a subject of great interest, because the concept is based on the premise of less energy expenditure for building operations. The US Department of Energy (DOE, 2009) estimates that the buildings are responsible for up to $70 \%$ of electric energy consumption in the USA. The costs for such housing projects may increase even more, if the overall costs throughout the life cycle are not taken into account.

In particular, more research is necessary on the response of specific income groups, including low-income households (Jeffries, 2012). However, recent efforts aiming a more sustainable society require a growing level of attention on social housing projects (Mulliner et al., 2013).

Smart building research is commonly explored in commercial buildings and less studied in the context of social housing. The ICE-WISH project, an acronym derived from smart control - reductions in water and energy waste in European Social housing, is one of the first attempts at evaluating benefits and barriers of smart building concepts adoption to low-income household consumers (ICE-WISH Project, 2014).

Social housing is commonly defined by comparing expenditures on housing with regard to family income (Hulchanski, 1995). The traditional form of considering social housing is to evaluate housing cost compared to income; however, this indicator may lead to a simplistic and unsustainable manner of considering financially affordable housing (Mulliner et al., 2013). Rents and mortgages are just a part of the entire cost of housing. Energy costs pose significant burdens to low-income households and improving the 
energy efficiency of social housing also helps to reduce these costs (Salvi del Pero et al., 2016). Housing production for low-income families should also consider the impact, which large-scale construction has on the use of a broad range of complementary resources (e.g., water, sewage, public transportation networks, education and health) (Maricato, 2009; Campbell, 1999).

Barriers to the adoption of smart buildings by social housing should be identified and studied carefully (Balta-Ozkan et al., 2013), especially in the context of developing countries (Ahmed, 2013). Barriers to the adoption of smart buildings in Brazil are a relevant theme, because this country has one of the largest social housing construction programs in the world. From 2009 to 2014, 3.75 million social housing units were constructed within the first and second phases of the program My House, My Life (MCMV) (Brasil - Presidency of Republic, 2014). Brazil also leads the Latin American Green City Index (Friederich and Langer, 2010) and ranks fourth in the world in sustainable buildings outside the USA (GBC, 2015).

A lack of knowledge concerning these barriers could delay the design and construction of environmentally sustainable buildings. In this context, this paper aims to diagnose the main barriers to the adoption of the smart building concept in social housing projects through literature review and case studies. The goals of this study are:

- review literature on social housing, smart buildings, barriers to smart buildings and social housing

- diagnose the main barriers to the adoption of smart homes and buildings concepts and technologies in Brazilian social housing projects

- compare the barriers diagnosed in the expert interviews with those described by the literature

- discusses possible solutions and guidelines to overcome such barriers, and propositions that can be improved into hypothesis for later empirical testing.

The paper is structured as follows: Section 2 reviews the literature regarding the definition of smart buildings; barriers to adopting smart buildings concepts and technologies. Section 3 outlines the methodological approach. Sections 5 and 6 outline the discussions and final remarks of this study.

\section{Background: smart buildings and key barriers}

\subsection{Smart buildings}

The 'smart' label is related to the use of this information for decision-making about when the consumer should generate, store or consume electricity (Snape, 2011). In principle the term 'smart building' may refer to any form of edifice or 'multi-dwelling units' (MDU), contained within one building or several buildings.

The term smart building was first used in the 1980s in the USA and it has focused on using 'building automation systems' (BAS) that control heating, air conditioning and the building security systems. More recent definitions of smart buildings focus on the use of 'structures connectivity solution' (SCS) for providing a common cabling solution on which the various building services can be delivered (e.g., data networking, telephony, 
environmental controls, security systems, etc.) (Rangrez, 2013). One of the benefits of installing smart technologies is to make the effects of the user behaviour pattern on energy consumption better known (Snape, 2011), however these benefits can only be fully obtained by engaging the end users (Anda and Temmen, 2014).

Smart buildings encompass the following principles: optimised modelling of cooling and ventilation equipment enables the system to spend a minimum quantity of energy for providing the desired level of comfort; a smart building will be operationally leaner where fewer people are inside; analysis algorithms will enable the proactive maintenance of equipment, which will detect problems; dynamic consumption of energy from the capturing of electricity market signals and the alteration of use in response, a smart building will ensure lower energy costs and it will generate revenue from the sale of charge reductions back to the electric grid.

Heating, ventilation, and air conditioning (HVAC) is a candidate for providing the much needed price elasticity of demand. HVAC systems are responsible for about $30 \%$ of total energy use in north-American housing (Liang et al., 2012). The demand for HVAC is more flexible than other housing demands because it is possible to change heating and cooling during peaks in demand without significant loss of comfort. Thermal storage in the building can be used for such, in combination with a BMS (Gungor et al., 2011).

Building automation is key to make more efficient operation of the building and also to the integration of buildings to smart grids (Gungor et al., 2011) and other external applications such as cloud computing. The smart grid concept involves the use of an improved information system to match energy consumption with production in a situation of great variability over time (due to the large percentage of renewable energies in the offer mix) (Snape, 2011). Additionally, the micro generation of energy in the home can give the user a closer relationship with their pattern of energy consumption, revealing the effects that habits from users have on electricity consumption and on the primary supply for generating this electricity.

The motives that have driven the change towards smart grids, as a better way to coordinate the supply and demand of electricity, include the fact that users are charged fixed prices, that is, they have little incentive to reduce demand when the grid approaches full capacity (Ipakchi and Albuyeh, 2009), besides the need to move towards renewable energy. Although these technologies permit the efficient gathering of data and two-way communications between users and the grid, the dynamic variation in prices (as a means to balance supply and demand) will only make sense if the users could manage their demand for electricity (Liang et al., 2012). The smart building can reduce energy costs and generate revenue by selling the reduction of charge back to the grid. This is possible by receiving signals from the electricity market, indicating the need to change use as a response.

Sources of renewable energy are a crucial component of the smart building. Besides ensuring the use of a sufficient quantity of technologies, the mismatch between consumption and production of renewable energy must be solved. To cope with the advances in energy innovation, increasing investment funding will be necessary. Crowdsourcing energy investment could be an alternative to create more environmentally friendly energy projects (Myers, 2015). 
Smart grid technology depends on smart meters (advanced metering infrastructure AMI) that use wireless connections with the power utility to provide consumers with hourly data on energy use, providing the company with up to date readings without the need for onsite reading of the meter. The smart meter is an advanced energy meter that obtains information from end user devices, measures consumer energy consumption, and provides additional information to the utility company or the system operator. Several sensors and control devices, supported by dedicated communication infrastructure, are used in the smart meter.

Smart meter systems use two basic types of communication technology: radio frequency (RF) and power line carrier (PLC) for sending data (Zheng et al., 2013). The display at the home helps the resident see how much energy is being used different times of day, month or year, which can help cut energy use and consequently be more efficient. In the future, this technology is expected to lead to the creation of innovative tariffs and personalised plans aligned to lifestyle and energy consumption (Uswitch, 2014). A significant percentage of social housing is located in MDU, and these buildings present a challenge to the employment of smart meters because they require proper communication infrastructure between components that may include electricity and gas meters, in-home displays, among others. Energy meters are commonly not located in the apartment, but rather in common areas or spread around the building.

Experiences with issues related to smart grids have revealed that end users engage, to a degree, with changes in habits, such as (Snape, 2011): adoption of smart meters for two-way data communication to accurately measure consumption; change in consumption in response to a signal (through in-home displays), with the desired level of energy conservation or change in consumption level; response to demand system (direct load control) to automatically reduce non-critical elements of consumption; adoption of efficient household appliances to reduce demand.

\subsection{Barriers to adopting smart buildings concepts and technologies}

Several barriers can delay the implementation of smart building concepts and technologies in mass-market social housing projects. Urban sprawl, especially from informal settlements, and the need to provide housing for so many inhabitants makes the adoption of smart building standards and concepts in large cities problematic. These barriers and the literature surrounding them are discussed in this section.

Edwards and Grinter (2001) were the first researchers to contribute to understanding the key barriers preventing the adoption of smart concepts and technologies into homes and consequently in DMUs. The authors highlight the following barriers: interoperability - the ability of equipment, devices, appliances and systems from different vendors to operate together; administration - the expertise and know-how required for a system operation and maintenance; reliability - the interconnection of diverse technologies with different tolerances poses a risk of failure or malfunctioning; systems intelligence and behaviour inference - systems that rely on inference will never be right all of the time; and security - the safeguarding of personal data. 
Over time, others barriers were identified: the retrofitting of existing homes and buildings, interoperability, costs (associated with the purchase and installation of smart devices) and usability (i.e., an intuitive/user-friendly interface) (Holroyd et al., 2010). Ciesielska and $\mathrm{Li}$ (2011) add to this list the lack of understanding of user needs and infrastructure solutions (i.e., technical skills and capacity to install them) as key barriers.

More recently, Balta-Ozkan et al. (2013) suggested that complexity (i.e., smart homes programs are complex); loss of control and apathy (i.e., monitoring of daily habits is perceived as intrusive and controlling); smart technology as divisive, exclusive or irrelevant (i.e., smart technology excludes those who are not literate) and trust (i.e., if smart technologies and services would really save customers money).

Greenough (2015) identified in the following barriers: High prices, coupled with limited consumer demand and long device replacement cycles (i.e., users will compare non-smart with smart devices and technologies to see if the benefits make up for the price differential) and technological fragmentation within the smart building ecosystem. The technological fragmentation within the smart building creates interoperability problems and making it confusing for the consumer to set up and control multiple devices.

Part of the barriers towards adopting smart grid and smart meter concepts is related to how the government and suppliers will conduct this transition. The plans for installing smart meters in social housing also face barriers related to communication with consumers (Gosden, 2014). Additional difficulties emerged in relation to how much data energy suppliers could access from the residential smart meters and whether this supplier could share these data with third parties. One of the concerns that began to be raised is about the privacy of energy consumption data. Exposure to these data could lead to several privacy problems that must be addressed before consumers can be convinced to use smart meters (Saputro and Akkaya, 2014).

Other barriers are regulatory in nature. Climate change policies are inducing the transformation in energy systems, and to obtain this, proper regulation of power grids and grid users will be necessary. Traditional regulation has been progressively changed in terms of focus and objectives. New areas have entered the regulatory agenda and the challenge to promote innovation has generated several initiatives (Schiavo et al., 2013).

However, much focus on technology and economic incentives could become a barrier. The institutional barriers that Verbong et al. (2013) identify include the domain of privacy, degree of control, lack of interest or time, and difficulty to change consumer routine behaviour. The analysis shows a tendency to attribute more attention to users in new smart grid projects. The extent to which users are willing to accept changes in their homes and daily routines will not only shape how the smart grid will look, but also the impact on the chances for success in implementation (Verbong et al., 2013). In Holland, additional pressure on the power grid is presented by the ageing of the electric infrastructure (Verbong et al., 2013). In Brazil, the current electrical system (power grid) is costly, unreliable and expensive for consumers (Emmanuel, 2014).

The pattern of the electricity consumption dynamics is influenced by consumer behaviour; therefore, the transition to smart grids will require knowledge of how to make this transition and of the behavioural change among these social players (Snape, 2011).

In Brazil, the following barriers to smart building adoption are observed (MME, 2014): 
- Safety requirements for solar system installations, considering people (users, installers, concessionaires, etc.) and installations.

- High investments for micro and small electricity generators, considering the efficiency limitations due to size (combustion generators) or to the small load factor corresponding to intermittent sources (photovoltaic solar and wind). This implies an installed Megawatt/hour cost higher than that for large plants.

- Regulatory sphere: Supply of surplus electric energy to low-voltage distribution grids and the non-regulation of the distributor's role in this situation and remuneration for this surplus electricity.

- Definition of how small generators and concessionaires will share responsibility for damages to the distribution system and third party equipment.

- Definition of how system operation and maintenance costs will be shared.

Cunha (2011) mentioned as barriers in the process of adopting smart building technologies in Brazil: lack of regulation in the distribution service; energy market structure lack adaptations for inclusion of small producers; high costs for the smart building technologies, their degree of maturation and related factors of scale; introduction of an appropriate communications infrastructure for large volumes of data and that operates in an integrated manner; lack of consumer engagement in smart building concepts and technologies. It is estimated that are 23 million electromechanical meters in low-income housing, the total cost for installing smart meters in social housing is around BRL 6.4 billion (MME, 2014). Smart meter implementation costs are the 'tip of the iceberg', since the greatest cost is for implementing the supporting infrastructure.

Additional barriers to the adoption of smart building concept may be related to the electrical system setting in Brazil (Galo et al., 2014): obsolescence of distribution system assets; high level of technical and non-technical losses; the duration of power interruptions per consumer/year has grown in recent years; system recovery is slow and precarious; slow modernisation of the grid and use of smart grids. National macroeconomic barriers related to the residential market can also influence the adoption rate of the smart building concept in developing countries. It can be observed that in China, for example, the prices for social housing building units fell sharply in 2014 due to lower GDP growth and the willingness of developers to offer price discounts (Noble, 2014).

\section{Research method}

For studying barriers to the adoption of the smart building concept in social housing projects, the key players in this process (e.g., Social Housing Organizations, constructors, utility companies, ICT service providers and integrators and universities) should be considered. The methodology used in this study follows these steps: 
- Based on literature review (Section 2), identify the main barriers to the adoption of smart buildings concepts in social housing projects.

- Select and conduct interviews with experts in this field of knowledge to identify barriers to implementing the smart building concept in social housing.

- Compare the main statements from the literature review with the barriers identified in the interviews. Suggest public policy strategies to mitigate these barriers and propositions that can be improved into hypothesis for later empirical testing.

The study was conducted from 2012 to 2015. Initially, papers in databases (Scientific ISI, Science Direct and Google Scholar) using the key words 'smart building'; 'smart home'; 'social housing'; 'smart grid' and 'smart meters' were collected. Then, these words were conjugated with 'barriers', 'challenges', 'My House, My Life' and 'Brazil'. After initial screening by title, the abstracts were read and the papers relevant to this study were selected. The literature review revealed that the study of this topic is still in its initial phase.

Therefore, the main research question for this study is 'What are the main barriers to the adoption of smart building concepts in social housing projects?' According to Yin (2003), the adoption of study questions for case studies such as 'What' is appropriate when the object of study focuses on contemporary events, as in adopting the smart building concept in social housing projects. Additionally, the experts prove relevant to the study because the question focuses on technical or process-related knowledge, and in this sense, they have access to the decision-making process and people. Therefore, the 'Expert Interviews' method was used, which is based on the assumption that experts have special knowledge, which is related to a field (Bogner et al., 2009). The nature of the interviews with experts was explorative, given that few studies investigated this subject. The choice of interviewed was based on their knowledge with smart buildings concepts, technologies and solutions and social housing, as evident from their participation in conferences, lectures and papers in magazines and newspapers, indications by NGOs. A series of in-depth interviews were made, through an open questionnaire, followed by comments to these answers. The expert interviews were conducted throughout March 2015. To gain greater insights on the phenomenon, the unit of analysis in this study was identification of barriers to the adoption of the smart building concept in social housing projects.

The answers were recorded, transcribed and categorised in basic statements, in terms of similarities. After this phase, the information was compiled down to a smaller set of general headings and it was sent back to the experts for analysis of the content. With a smaller set of topics identified, a thematic comparison was made between the main statements and literature review. A potential list of barriers was established and an attempt was made to develop explanations for each barrier identified. Additionally, an attempt was made to suggest public policy strategies to mitigate these barriers. Section 4 presents the main results of these interviews. 


\section{Research results}

The results of this study are presented in three sections: a context of the current situation in Brazil in relation to implementing the smart building concept and correlated technologies; the barriers to adopting the smart building concept in social housing and guidelines and suggestions for overcoming these barriers.

\subsection{Summary of factors affecting smart building concepts and technologies adoption in social housing: expert interviews}

The results of this study indicates that a series of technologies with smart characteristics have been implemented in the national energy distribution market (and, in a smaller scale, in the energy generation market). However, the adoption of smart building technologies is still insipient in the Brazilian construction market. At present, the main components and technologies used in smart buildings in Brazil are imported. For example, the silicon cells that comprise the photovoltaic panel are usually purchased in China, which in turn buys the raw silicon in Brazil (owner of the world's largest reserves). Therefore, another challenge is to create an entire production chain for these technologies in Brazil. Suppliers are installing plants, but there is the fear of assuming early adoption costs for smart technology in a context where the regulatory framework is not completely defined.

The interest in adopting the smart building concept has the support of top management, of stakeholders in energy utilities and construction companies, and the mobilisation for this to happen in these organisations is already visible. However, the adoption process for this type of technology in construction or in existing buildings is in its initial phase. One of the reasons for this situation is that in most Brazilian regions (North, Northeast and Midwest and some regions in the South of Brazil), the electric grid infrastructure is precarious, with the Southeast the exception. This means the initial projects for installing the smart building concept tend to be implemented in this region of the country.

Usually, when smart technology is used in building construction in Brazil it is to service large corporate customers from energy utility companies or large building constructors. One example is the Belo Horizonte new football stadium, built for the 2014 World Cup, which has enough solar panels units to generate its own energy for operation, and to sell the excess electricity to a local energy company.

From the perspective of government regulation, the general conditions have been defined for assessing micro generation and mini generation distributed in the electric energy distribution systems, and for the compensation system for surplus energy, as well as the regulation of smart meters for low voltage consumer units (including social housing).

The water crisis that took hold in some states in Brazil in mid-2014 caused an increase in megawatt/hour prices for energy from around $120 \%$. Paradoxically, this has driven the adoption of photovoltaic and wind energy, which have a higher cost per megawatt/hour of energy, respectively, with hydroelectric energy just below that level. One of the main challenges is the need for more effective actions in relation to adopting smart technologies by the energy utilities companies. If these companies are willing to 
develop these alternative energies, infrastructure in social housing constructions will be enabled.

\subsection{Summary of barriers affecting smart building concepts and technologies adoption in social housing: expert interviews}

In this section is presented and discussed barriers that might hinder adoption of smart building concepts and technologies in social housing. These barriers emerged from the expert interviews analysis.

\subsubsection{Problems with availability of skilled and specialised jobs in smart buildings concepts, devices and solutions}

The use of techniques and technological materials require skilled and specialised labour. New knowledge in computer and telecom areas is needed for working with these technologies. The need for specialised jobs goes beyond the simple sale of technology. It demands the integration of technologies in bundles of smart building solution packages which requires specialised services from a broad range of professionals. This requires a workforce with a minimum of education in this field of knowledge. The labour supply in Brazil with these characteristics is reduced (i.e., Brazil has much less engineers per inhabitant compared to Korea, Japan, China and the USA). Another factor is the quality of this workforce, which needs improvements in technical and technological education systems.

\subsubsection{Sharing the infrastructure costs from smart grids platforms, systems and interfaces with stakeholders}

The replacing of residential smart meters is just part of the installation costs for a smart grid system. Higher costs will be incurred in the installation of a safe communications platform, in systems and interfaces. However, ANEEL, the Brazilian electrical energy regulatory agency, only recognises costs of smart meters. It is necessary to be clear about how to share these costs. Besides the expensive nature of the infrastructure to be installed, local industry must produce these new technologies in Brazil, and this demands a regulatory environment that favours these investments.

\subsubsection{Low consumption of energy in Brazilian social housing}

In the USA, the household electric consumption it is around $11.700 \mathrm{kWh} /$ year, compared to $1.850 \mathrm{kWh} /$ year in Brazil. The social housing electric consumption is estimated to be even less, of around $1.200 \mathrm{kWh} /$ year. This divergence can be attributed to differences in household size and electrification rates. Despite the high number of residential consumers in Brazil (approx. 45 million), social housing is estimated to be responsible for $50 \%$ of the total number of residential consumer units. Therefore, consumption per capita is still very low, reflecting the social-economic conditions of these consumers. It means, paradoxically, that the electricity utilities companies do not have a great interest in smart technologies for this market because the low residential energy consumption rates. Micro energy generation is also not stimulated, because social housing units are usually 
compounded of single phase electric units, which has a minimum annual cost of $360 \mathrm{kWh} /$ year.

\subsubsection{Energy micro generation market is still incipient in Brazil}

Although solar photovoltaic energy generation has a comparative advantage in Brazil, given the geographic location, few projects have been implemented and generation capacity is limited. However, further incentives to encourage small-scale renewable systems are expected due to a series of recent events, such as, the prolonged drought that put Brazil's water supply and energy matrix into stress (roughly $75 \%-80 \%$ of the Brazil's generation matrix came from hydro plants);

\subsubsection{Theft and fraud in the Brazilian electricity distribution system}

Theft and fraud (e.g., security seal violation and direct or indirect changes to the mechanical disc of electromechanical meters) in Brazilian electricity distribution system is considered a problem. Every year, energy utilities companies lose approximately USD 5 billion because of this problem (Galo et al., 2014). One of the main barriers to the adoption of the smart grid concept is its capacity to prevent fraud and illegal connections (theft). Fraud refers to registered consumers who make changes in the system to use more energy than recorded consumption. Theft occurs when users directly deviates electricity from the distributors, whereby the energy is not accounted. Electricity theft was detected by utility energy companies even with the use of electronic/smart meters (Faria et al., 2014).

\subsubsection{Precarious electric grid infrastructure in most of Brazil}

In most parts of the country the electricity distribution system is obsolete, in need of replacement, due to the obsolescence of distribution assets and the precarious and slow recovery of the system. A worsening in energy supply quality can be observed in recent years, especially in the frequency and duration of power outages. Additionally, the energy distribution system does not use automated systems and its management is done conventionally.

\subsubsection{Standardisation of the tax system for energy micro generation}

In the case of micro generation, the excess of energy can be directed to the network, creating an 'energy credit'. The positive balance of this energy credit cannot be reversed in cash, but can be used to reduce consumption costs by another unit (in the same area) if the resident does not use the energy credit. However, upon using the credit, he/she must pay the ICMS tax (a state tax). This results in a low financial return for micro generation projects and payment of taxes on one's own generated energy. The tax system, also differ in the Brazilian states, leading to different adoption rates in the states for the concepts and technologies related to micro energy generation markets. 


\subsubsection{Lack of financial and financing incentives for adopting smart building technologies}

The adoption of a financing program and an incentive for adopting energy micro generation and smart meters can contribute to an increase in the adoption of these technologies, but that depends on public and private policies for incentives and financing. At the moment, there are no incentive policies in place and the cost for adoption and investment in such technologies falls on service users.

\subsubsection{Lack of a regulatory environment favourable to adopting the concept smart building}

In the current stage of technology and development of the electricity market, it is necessary to support the smart buildings concept through incentive instruments. These incentives can be divided into financial incentives, public funding and regulatory policies. A regulatory policy to direct the demand to more efficient and low carbon energy products and services would foster the concept adoption.

\subsubsection{Residential energy users may have little awareness energy use}

It is people who use energy, and not buildings themselves. Even in exactly identical affordably homes, energy consumption can differ, depending in the user consumption behaviour. Feedback about energy use is important, but the context is also important (e.g., direct or indirect feedback).

\section{Discussions}

According to the interviews conducted there are strong intentions on the part of energy utilities companies to adopt smart building concepts, however a series of difficulties must be dealt with for this to actually happen. Possible solutions and guidelines are proposed in this section for dealing with such barriers, based on the consulted literature and results of interviews presented in Sections 4.1 and 4.2.

The research crystallised outlines of four majors' barriers categories for the adoption of smart buildings concepts, technologies and solution into social housing (Table 1). These barriers can be summarised in aspects related to:

1 economic

2 policy

3 social

4 technical.

Once the four majors' barriers were identified, we detailed possible solutions, for the identified barriers identified. 
Table 1 Four majors' barriers categories for the adoption of smart buildings concepts, technologies and solution into social housing

\begin{tabular}{|c|c|c|c|}
\hline Aspects & Barriers & $\begin{array}{l}\text { Literature smart } \\
\text { (home, building) } \\
\text { and social } \\
\text { housing }\end{array}$ & $\begin{array}{l}\text { Expert } \\
\text { interviews }\end{array}$ \\
\hline \multirow[t]{8}{*}{ Economic } & Administration & $\sqrt{ }$ & \\
\hline & Costs & $\sqrt{ }$ & \\
\hline & Limited consumer demand & $\sqrt{ }$ & $\sqrt{ }$ \\
\hline & Long replacement cycles & $\sqrt{ }$ & \\
\hline & Ageing of electric infrastructure & $\sqrt{ }$ & \\
\hline & Macroeconomic barriers & $\sqrt{ }$ & \\
\hline & Lack of skilled and specialised workers & & $\sqrt{ }$ \\
\hline & Incipient micro energy generation market & & $\sqrt{ }$ \\
\hline \multirow[t]{5}{*}{ Policy } & Regulatory barriers & $\sqrt{ }$ & $\sqrt{ }$ \\
\hline & $\begin{array}{l}\text { Sharing infrastructure responsibilities and } \\
\text { costs }\end{array}$ & $\sqrt{ }$ & $\sqrt{ }$ \\
\hline & Fragmented energy market structure & $\sqrt{ }$ & \\
\hline & Tax system for energy micro generation & & $\sqrt{ }$ \\
\hline & Lack of financial and financing incentives & & $\sqrt{ }$ \\
\hline \multirow[t]{7}{*}{ Social } & Usability & $\sqrt{ }$ & \\
\hline & Lack of understanding user needs & $\sqrt{ }$ & \\
\hline & Loss of control and apathy & $\sqrt{ }$ & $\sqrt{ }$ \\
\hline & $\begin{array}{c}\text { Smart technology as divisive, exclusive or } \\
\text { irrelevant }\end{array}$ & $\sqrt{ }$ & \\
\hline & Communication with consumers & $\sqrt{ }$ & \\
\hline & Difficulty to change consumer behaviour & $\sqrt{ }$ & \\
\hline & $\begin{array}{l}\text { Theft and fraud in electricity distribution } \\
\text { system }\end{array}$ & & $\sqrt{ }$ \\
\hline \multirow[t]{8}{*}{ Technical } & Interoperability & $\sqrt{ }$ & \\
\hline & Reliability & $\sqrt{ }$ & \\
\hline & Systems intelligence and behaviour inference & $\sqrt{ }$ & \\
\hline & Privacy and data security & $\sqrt{ }$ & \\
\hline & Retrofitting of existing homes and buildings & $\sqrt{ }$ & \\
\hline & Complexity & $\sqrt{ }$ & \\
\hline & $\begin{array}{l}\text { Slow and precarious electrical system } \\
\text { recovery from power interruptions }\end{array}$ & $\sqrt{ }$ & \\
\hline & Interoperability & $\sqrt{ }$ & $\sqrt{ }$ \\
\hline
\end{tabular}


Possible solutions, for some of the identified barriers in literature can be observed below:

- A change in the regulatory environment to provide predictability to stakeholders who want to invest and to permit the sharing of infrastructure costs for adopting smart building concepts and technologies.

- Regulation in the energy market structure for inclusion of small/micro energy producers. Small/micro energy producers deliver their own generated energy to energy utilities companies at zero cost, and they receive the return as a credit with the payment of taxes. A change in the tax system, allowing the small/micro energy generators to sell the excess electricity and to purchase energy with alternative mechanisms (e.g., prepaid energy), would be beneficial for the adoption of the concept.

- High costs of smart building technologies, the degree of technological maturity within this field, and the low diffusion of production technologies in the market can be mitigated by tax cuts (especially imports) to stimulate the adoption of technologies related to smart buildings that prove to be more efficient environmentally.

- Lack for an appropriate communications infrastructure for big volumes of data, which operates in an integrated manner, can be stimulated by the adoption of technological standards and communication solutions that prove effective.

- Consumer engagement can be achieved by adopting marketing and information campaigns aimed at the social housing energy consumer. It would be desirable a study of how low-income energy consumers adopts these smart building technologies and their engagement in a behaviour of low energy consumption.

Other solutions, of the current setting of implementing the smart building concept in social housing, can be applicable in the barriers diagnosed in the interviews and literature and include:

- $\quad$ Problems such as quality and availability of specialised workforce can be solved by developing courses by official associations and universities for technical development in smart building technologies. Increase investments in smart building technology courses. Professional certifications by associations can assist in identifying and increasing the qualification of available labour.

- Sharing of the high costs of infrastructure can occur if ANEEL recognises the inherent costs incurred by those agents involved and permits innovative cost sharing plans for installing this infrastructure.

- Low residential energy consumption is a complex problem in Brazil. For low-income families, energy costs consume a large portion of after-tax household income. Federal or state government assistance would help to reduce the minimum cost that social housing units pay for the electrical system availability (360 kWh/year), making the smaller micro energy generation projects economically viable.

- The size of the energy micro generation market can be expanded by adopting lower cost technologies for energy generation, and by reducing payback times related to micro generation projects. 
- Theft and fraud in the electric system can be mitigated by adopting smart building technologies, and by technologies that impede the adulteration of consumption data. The new challenges for securing and protect assets from energy utilities companies and consumers will require expertise and new methods on data analysis and security requirements.

- Precarious electric grid infrastructure in most of Brazil can be mitigated by increasing investments in electric system infrastructure, and furthermore, the reduction of infrastructure inequities in the different regions of the country.

- Lack of financial and financing incentives can be mitigated by developing incentives for smart building concepts and technologies adoption in social housing programs. However, the design of these incentives should consider the whole supply network, in order to coordinate actions across firms (with its own priorities and goals).

- Low-income energy users would have greater awareness of how much energy they use, by providing them with competitively priced individual smart meters, which improve accuracy about actual energy consumption, including historic and comparative feedback.

Next, we discuss and provide implications for research, industry and also discuss the limitations of the study.

\subsection{Implications for theory and research}

The outcome of this research has a number of implications for research. The barriers for smart building concepts and technologies adoption identified a number of barriers and suggestions to overcome them. Why then the potential to integrated smart buildings concepts into social housing is realised to such a limited extent? The findings in the interviews and previous literature demonstrate (e.g., Toft, 2014; Oliveira et al., 2015) that not all social housing residents are likely to adopt Smart Building concepts and technologies. The research results suggest that to overcome adoption barriers from users, the identification of which users to approach at first basis would be desirable. The findings in the literature and evidences from expert interviews lead to a first proposition.

Proposition 1 A higher willingness, of a specific group of social housing dwellers, to accept and adopt the use of smart building concepts and solutions will positively affect the diffusion of smart building concepts in social housing.

An overall claim from the interviewed is that the smart building concept should add more value than its costs, because social housing has its main focus on affordability. However, for building project developers, affordability usually means the lowest available cost in a determined point of time, instead of the lowest housing total cost of ownership. Therefore, Smart buildings concepts and solutions are regarded as a cost-adding rather than value-adding factor, when considering social housing. Therefore we propose: 
Proposition 2 Integration of smart building concepts, devices and solutions in the early phases of design, integration and implementation of social housing projects will result in reduction of household energy consumption, and therefore, a lower total cost of ownership.

Energy utilities companies in Brazil have been struggling with how to integrate renewable energy micro generation into their systems and business models. Future financial and financing incentives may eventually erode the economics of the energy utility company, particularly if it is a high-cost operator. In addition, rooftop solar panels may have, in future, the tendency to reduce sales for power distribution companies. Based on this discussion we suggest:

Proposition 3 Design of financial and financing incentives should consider the whole supply network, related to energy production and distribution, smart buildings and social housing in order to coordinate actions across firms, and thus have higher rates of smart buildings concepts and technologies adoption.

\subsection{Implications for industry}

Smart building concepts and technologies, used in the wrong context, will probably default to unwise modes of operation. As Collins (2013) suggest, the best intelligence in social housing buildings resides with the occupants. If so, the challenge for designers, manufacturers and construction companies is to support social housing buildings with appropriate and understandable systems that have readily usable control interfaces, and which give immediate feedback on their performance. This range of conditions for best-fit technology, when applicable for social housing projects in developing countries, should have: minimum conflicts in operation; be inherently energy efficient; include a device to store energy (due to power failures); be directed to mid-to-low tier consumer; obtain the right balance between low cost and right superior technology; involve micro energy generation; reduce complexity to the consumer (due to consumer apathy); have a fast recover from power failures; be easy to build, maintain and operate.

\subsection{Limitations}

The study was conducted within a time frame of a year. Therefore, acceleration in adoption of smart buildings concepts and technologies in social housing may lead to outdate some of the findings. The limitation in this study is related to the data collection and explanatory analyses, which are typical of qualitative studies. Besides that, the main information of the study was obtained through expert interviews, and respondent bias could exist. Another important limitation is that just seven experts interviews were considered in the study, because of the technology and social boundary character of this study, avoiding any sort of generalisation of results obtained.

\section{Final remarks}

Our study analyses the main barriers to the adoption of smart buildings in social housing projects in Brazil, and developed possible solutions and guidelines for overcoming them. 
Expert interviews, which had supported previous findings on smart home and building concepts adoption, indicated as main barriers: limited consumer demand; lack of skilled and specialised workers; Incipient micro energy generation market; regulatory barriers; sharing infrastructure responsibilities and costs; tax system for energy micro generation; lack of financial and financing incentives; loss of control and apathy; theft and fraud in electricity distribution system; slow and precarious electrical system recovery from power interruptions. These perspectives only partly correspond to those of literature. Thus, while both literature and experts seems to agree on some barriers (e.g., limited consumer demand and loss of control and apathy), some barriers were only identified in the expert interviews (i.e., lack of skilled and specialised workers; incipient micro energy generation market; tax system for energy micro generation; lack of financial and financing incentives; theft and fraud in electricity distribution system).

A summary of the main results of this study is shown below:

- The process of adopting smart building concepts and technologies in social housing projects in Brazil is in its initial phase.

- In relation to the main barriers for the adoption of smart buildings concepts, technologies and solution into social housing identified within this research are:

1 economic

2 policy

3 social

4 technical.

- Once the majors' barriers were identified, we detailed possible solutions and propositions for the identified barriers.

It is hoped that this study can contribute to enriching knowledge on smart building technologies and their possible incorporation into social housing projects in Brazil. Additionally, this study can serve as a guide for stakeholders that decide to adopt this type of technology and construction, so they can handle the difficulties faced during the process with greater ease, casting a light on the barriers and proposing solutions and guidelines for overcoming them.

\section{References}

Ahmed, A. (2013) Energy Smart Buildings: Potential for Conservation and Efficiency of Energy, Pakistan Institute of Developing Economics, Karachi [online] http://pide.org.pk/psde/pdf/AGM29/papers/Ajaz\%20Ahmed.pdf (accessed 9 August 2014).

Alshuwaikhat, H.M. and Abubakar, I. (2008) 'An integrated approach to achieving campus sustainability: assessment of the current campus environmental management practices', Journal of Cleaner Production, No. 16, pp.1777-1785.

Anda, M. and Temmen, J. (2014) 'Smart metering for residential energy efficiency: the use of community based social marketing for behavioural change and smart grid introduction', Renewable Energy, Vol. 67, pp.119-127.

ANEEL - Brazilian Agency of Electrical Energy (2014) Banco de informações de geração: capacidade de geração no Brasil [online] http://www.aneel.gov.br/aplicacoes/ capacidadebrasil/capacidadebrasil.cfm (accessed 30 September 2014). 
Balta-Ozkan, N., Davidson, R., Bicket, M. and Whitmarsh, L. (2013) 'Social barriers to the adoption of smart homes', Energy Policy, Vol. 63, pp.363-374.

Bogner, A. et al. (Eds.) (2009) Experten-interviews: Theorien, Methoden, Anwendungsfelder, VS-Verlag für Sozial wissenschaften, Wiesbaden.

Brasil - Presidency of Republic (2014) Meta do minha casa, minha vida 3 é entregar três milhões de moradias, afirma Dilma, Blog do Planalto, Brasília [online] http://blog.planalto.gov.br/ meta-do-minha-casa-minha-vida-3-e-entregar-tres-milhoes-de-moradias-afirma-dilma/ (accessed 9 August 2014).

Campbell, S.D. (1999) 'Green cities, growing cities, just cities? Urban planning and the contradictions of sustainable development', in Satterthwaite, D. (Ed.): Sustainable Cities, Earthscan Publications; Island Press, UK; USA.

Ciesielska, M. and Li, F. (2011) 'The connected home: from market barriers to business model solutions', in Skersys, T., Butleris, R., Nemuraite, L. and Suomi, R. (Eds.); Building the E-World Ecosystem, Vol. 353, pp.189-199, Springer-Verlag, Berlin.

Collins, B. (2013) The Balanced European Conservation Approach Project-Behaviour Change in Social Housing, Centre for Environment \& Society Research Working paper Series, Birmingham City University.

Cunha, A.P. (2011) Bases conceituais da implantação de redes elétricas inteligentes de distribuição de energia elétrica, $\mathrm{PhD}$ thesis, $\mathrm{PhD}$ in Engineering, Polytechnic School, University of São Paulo, São Paulo, Brazil.

Department of Energy (2009) Buildings Energy Data Book, DOE, Washington [online] $\mathrm{http}$ ///buildingsdatabook.eren.doe.gov/ (accessed 28 September 2014).

Edwards, W.K. and Grinter, R.E. (2001) 'At home with ubiquitous computing: seven challenges', Proceedings of the Third International Conference on Ubiquitous Computing, pp.256-272, Springer-Verlag, Atlanta, Georgia, USA.

Emmanuel, A. (2014) 'ComEd 'smart grid' upgrades kicking off in uptown in 2014' [online] http://www.dnainfo.com/chicago/20140204/uptown/comed-smart-grid-upgrades-kicking-offuptown-2014 (accessed 18 September 2014).

Faria, R.A., Fonseca, K.V.O., Schneider Jr., B. and Nguang, S.K. (2014) 'Collusion and fraud detection on electronic energy meters: a use case of forensics investigation procedures', 2014 IEEE Security and Privacy Workshops, 17-18 May 2014, San Jose.

Friederich, J. and Langer, H. (2010) Latin American Green City Index, Economist Intelligence Unit, London.

Galo, J.M., Macedo, M.N.Q., Almeida, L.A.L. and Lima, A.C.C. (2014) 'Criteria for smart grid deployment in Brazil by applying the Delphi method', Energy, Vol. 70, No. 1, pp.605-611.

Gosden, E. (2014) 'Energy giants call for review of smart meter roll-out to save consumers $£ 1.8$ bn', The Telegraph [online] http://www.telegraph.co.uk/finance/newsbysector/energy/ 10613535/Energy-giants-call-for-review-of-smart-meter-roll-out-to-save-consumers1.8bn.html (accessed 22 September 2014).

Greenough, J. (2015) 'The US Smart Home Market report: adoption, forecast, top products, and the cost and fragmentation problems that could hinder growth', Business Insider Intelligence.

Gungor, V.C., Sahin, D., Kocak, T., Ergut, S., Buccella, C., Cecati, C. and Hancke, G.P. (2011) 'Smart grid technologies: communication technologies and standards', IEEE Transactions on Industrial Informatics, Vol. 7, No. 4, pp.529-539.

Holroyd, P., Watten, P. and Newbury, P. (2010) 'Why is my home not smart?. Aging friendly technology for health and independence', in Lee, Y., Bien, Z. Z., Mokhtari, M., Kim, J. T., Park, M., Kim, J., Lee, H. and Khalil, I. (Eds.): Aging Friendly Technology for Health and Independence, Vol. 6159, pp.53-59, Springer-Verlag, Berlin.

Hulchanski, J.D. (1995) 'The concept of housing affordability: six contemporary uses of the housing expenditure-to-income ratio', Housing Studies, Vol. 10, No. 4, pp.471-491.

ICE-WISH Project (2014) [online] http://www.ice-wish.eu/uk/about-icewish/about-icewish.asp (accessed 30 June 2014) 
Ipakchi, A. and Albuyeh, F. (2009) 'Grid of the future', Power and Energy Magazine, Vol. 7, No. 2, pp.52-62.

Jeffries, M. (2012) 'Social housing smart meter project to test behavioural change' [online] http://analysis.smartgridupdate.com/policy-regulation/ social-housing-smart-meter-project-test-behavioural-change (accessed 30 August 2014).

Lee, Y.M., Fei Liu, L., Horesh, R., Chae, Y.T. and Zhang, R. (2013) 'Applying science and mathematics to big data for smarter buildings', Annals of the New York Academy of Sciences, Vol. 1295, pp.18-25.

Liang, Y., Levine, D.I. and Shen, Z.J. (2012) 'Thermostats for the smart grid: models, benchmarks, and insights', The Energy Journal, Vol. 33, No. 4, pp.61-95.

Maricato, E. (2009) 'Por um novo enfoque teórico na pesquisa sobre habitação', Cadernos Metrópole, Vol. 21, pp.33-52.

MME - Ministry of Mines and Energy of Brazil (2014) Relatório Smart Grid: Grupo de Trabalho de Redes Elétricas Inteligentes, MME [online] http://www.mme.gov.br/mme/galerias/ arquivos/acoes/Energia/Relatxrio_GT_Smart_Grid_Po rtaria_440-2010.pdf (accessed 18 September 2014).

Mulliner, E., Smallbone, K. and Maliene, V. (2013) 'An assessment of sustainable housing affordability using a multiple criteria decision making method', Omega, Vol. 41, No. 2, pp. $270-279$

Myers, T. (2015) 'What the energy sector can learn from Uber', The Wall Street Journal [online] http://blogs.wsj.com/experts/2015/03/31/what-the-energy-sector-can-learn-from-uber (accessed 31 March 2015)

Noble, J. (2014) 'China's housing headache in one chart', Financial Times [online] http://blogs.ft.com/beyond-brics/2014/10/30/chinas-housing-headache-in-one-chart/ (accessed 30 October 2014).

Oliveira, L.C.R. et al. (2015) 'Pre-installation challenges: classifying barriers to the introduction of smart home technology', Third International Conference on ICT for Sustainability, (ICT4S 2015), 7-9 September, pp.117-125, Copenhagen.

Rangrez, T.A. (2013) A Day in the Life of a Smart Building, Tandeed Projects, Etisalat [online] https://www.bicsi.org/uploadedFiles/BICSI_Website/Global_Community/Presentations_and Photos/Middle_East_and_Africa/2013_Dubai/08\%20Dr.Taseer\%20Tamdeed.pdf.! (accessed 30 June 2014).

Salvi del Pero, A. et al. (2016) Policies to Promote Access to Good-Quality Affordable Housing in OECD Countries, OECD Social, Employment and Migration Working papers, No. 176, OECD Publishing, Paris.

Saputro, N. and Akkaya, K. (2014) 'On preserving user privacy in smart grid advanced metering infrastructure applications', Security and Communication Networks, Vol. 7, No. 1, pp.206-220.

Schiavo, L.L., Delfanti, M., Fumagalli, E. and Olivieri, V. (2013) 'Changing the regulation for regulating the change: innovation-driven regulatory developments for smart grids, smart metering and e-mobility in Italy', Energy Policy, Vol. 57, No. C, pp.506-517.

Smart Cities Council (2015) Smart Buildings: Key to Smart Cities, Smart City Council, India Chapter [online] http://india.smartcitiescouncil.com/article/smart-buildings-key-smart-cities (accessed 9 November 2015).

Snape, J.R. (2011) 'Understanding energy behaviours and transitions through the lens of a smart grid agent based model', ECEEE 2011 Summer Study Conference [online] $\mathrm{http}: / /$ www.academia.edu/614233/Understanding energy behaviours and transitions throug h_the_lens_of_a_smart_grid_Agent_Based_Model (accessed 4 June 2013).

Toft, M.B. (2014) Consumer Adoption of Sustainable Energy Technology: The Case of Smart Grid Technology, $\mathrm{PhD}$ thesis submitted to Business and Social Sciences, Aarhus University. 
Uswitch (2014) Smart Meters Explained: Smart Meters Are To Be Installed in Every Home in the UK by 2020 - But What is a Smart Meter, and What Difference Will They Make To Your Electricity Bills? [online] http://www.uswitch.com/gas-electricity/guides/ smart-meters-explained/ (accessed 19 September 2014).

Verbong, G.P.J., Beemsterboer, S. and Sengers, F. (2013) 'Smart grids or smart users? Involving users in developing a low carbon electricity economy', Energy Policy, Vol. 52, No. C, pp.117-125.

Yin, R.K. (2003) Case Study Research, 3rd ed., 181p, Sage Publications, Califórnia, USA.

Zainordin, B.N., Abdullah, B.M.S. and Ahmad, B.Z. (2012) 'Light and space: users perception towards energy efficient buildings', Procedia - Social and Behavioral Sciences, Vol. 36, pp.51-60.

Zheng, J.X., Gao, D.W. and Lin, L. (2013) 'Smart meters in smart grid: an overview', IEEE Green Technologies Conference (GREENTECH), pp.57-64, DOI: 10.1109/GreenTech.2013.17 Denver, CO. 